\title{
A rare case report: pregnancy with pancytopenia
}

\section{Yogesh Rajput, Uma N. Wankhede*}

Department of Obstetrics and Gynecology, B.J.G.M.C. and S.G.H., Pune, Maharashtra, India

Received: 04 October 2017

Accepted: 31 October 2017

\section{*Correspondence:}

Dr. Uma N. Wankhede,

E-mail: drumawankhede@ rediffmail.com

Copyright: (c) the author(s), publisher and licensee Medip Academy. This is an open-access article distributed under the terms of the Creative Commons Attribution Non-Commercial License, which permits unrestricted non-commercial use, distribution, and reproduction in any medium, provided the original work is properly cited.

\section{ABSTRACT}

Pancytopenia is reduction in all the three major cellular elements of blood, hence it is the simultaneous presence of anaemia, leukopenia and thrombocytopenia. Here we present a case of a 28-year-old female, G4P3L1D2 with previous LSCS with 30 weeks gestation with pancytopenia managed with steroids and transfusions.

Keywords: Normoblastic erythroid hyperplasia, Pancytopenia, Pregnancy

\section{INTRODUCTION}

Pancytopenia is reduction in all the three major cellular elements of blood, hence it is the simultaneous presence of anaemia, leukopenia and thrombocytopenia. It is not a disease entity but a triad of findings that may result from various disease processes, primarily or secondarily involving the bone marrow. ${ }^{1}$ The complete haematological work up with good clinical correlation is of utmost importance to evaluate the cause of pancytopenia and planning further investigations. ${ }^{2}$ During pregnancy it could be life-threatening for both mother and child. Treatment options are erythrocytes and platelet transfusions and immunosuppressive therapy. There is, however, no agreement about the optimal supportive care and treatment regime for this disorder during pregnancy. The most common aetiology of pancytopenia is aplastic anaemia followed by normoblastic erythroid hyperplasia and megaloblastic anaemia. While bone marrow failure syndromes and malignancies are important causes, certain non-malignant conditions such as infection and nutritional anaemia are equally important causes. ${ }^{3}$

We present a 28-year female G4P3L1D2 previous 1 LSCS with an uneventful medical history who was referred at 30 weeks gestational age as a case of anaemia with thrombocytopenia. Patient was admitted, investigated and diagnosed as a case of pancytopenia with bone marrow study showing normoblastic erythroid hyperplasia with myeloid:erthyroid ratio of 1:3. Patient was treated conservatively and delivered spontaneously at 38 weeks of gestation.

\section{CASE REPORT}

A 28-year-old female, G4P3L1D2 with previous LSCS with 30 weeks gestation, resident of Nagar, educated up to $10^{\text {th }}$ standard, registered and immunized at Civil Hospital Nagar, referred as a case of previous LSCS with anemia with history of 3-pint PCV transfusion in last 1 month. A detailed history of recent infection and any drug intake was taken, and a thorough clinical examination was done, and lymphadenopathy and hepatosplenomegaly were ruled out. Patient was investigated as case of anemia and laboratory values were as follows hemoglobin: 6.0g/dl; TLC: 3000/cumm; platelet count: 40,000/cumm. PBS showed normocytic normochromic anemia with thrombocytopenia, reticulocyte count $0.5 \%$, serum folate and vitB12 were normal while serum ferritin was raised $(756.28 \mathrm{ng} / \mathrm{ml})$, sickling test was negative and hemoglobin electrophoresis was within normal limits. Liver function tests and renal function tests were within normal limits. 
Haematologist reference was done in view of pancytopenia and patient was put on $\mathrm{T}$. Methylprednisolone $40 \mathrm{mg}$ OD and was advised bone marrow aspiration study.

Bone marrow aspiration report showed normoblastic erythroid hyperplasia with $\mathrm{M}: \mathrm{E}$ ratio of 1:3. Patient was managed conservatively by maintaining hematocrit above $20 \%$ by PCV transfusion and platelet transfusion to maintain platelet count above 20,000/cmm, patient received total 8 pint $\mathrm{PCV}$ and 8pint platelet till delivery. Tab. Methylprednisolone $40 \mathrm{mg}$ was given daily. Prophylactically injection Vitamin B12 were given $2 \mathrm{cc}$ IV weekly and tab folic acid $5 \mathrm{mg}$ daily were continued till delivery and iron preparations were withheld. Weekly ultrasonography was done to monitor the fetal growth. Weekly blood sugar levels values were done to rule out steroid induced glucose intolerance. Complete blood count was done twice weekly. Close monitoring for bleeding tendencies, any infections and foetal wellbeing was done which included DFMC, NST. Patient went into spontaneous labour at 38 weeks of gestation and delivered vaginally a normal healthy female baby weighing $2.8 \mathrm{~kg}$ without any complication. Patient was discharged on $10^{\text {th }}$ post-natal day and on discharge the laboratory values were hemoglobin: $8.4 \mathrm{gm} / \mathrm{dl}$; platelet count: 46000/cumm; TLC: 3600/cumm. Patient was advised weekly OPD follow up.

\section{DISCUSSION}

Pancytopenia is reduction in all the three major cellular elements of blood; hence it is the simultaneous presence of anemia, leucopenia and thrombocytopenia. It is not a disease entity but a triad of findings that may result from various disease processes, primarily or secondarily involving the bone marrow. ${ }^{1}$

The risk to the mother is mainly in the form of hemorrhage, sepsis and cardiac failure, while the fetus may suffer from growth restriction and even intrauterine death. Hemorrhage and sepsis are responsible for more than $90 \%$ of maternal mortality. ${ }^{4}$ Most of the fetal complications are due to maternal anemia. And along with these problems, maternal infections may lead to the development of chorioamnionitis and resultant preterm labor and birth. ${ }^{5}$ In the literature, fetal thrombocytopenia, placentomegaly, and severe oligohydramnios have also been reported.

This potential life-threatening disease has a relatively good prognosis for both mother and child after optimal treatment. There is, however, no causal relationship between pregnancy and pancytopenia. ${ }^{6}$ Transfusion during pregnancy is the first-choice treatment. To avoid maternal and neonatal complications, a minimum of hemoglobin level $>70 \mathrm{~g} / \mathrm{L}$, platelet count $>30 \times 109 / \mathrm{L}$ and WBC count $>3 \times 109 / \mathrm{L}$, are recommended. ${ }^{7}$ Close monitoring on blood routine, maternal complications and active supportive treatment are recommended. Vaginal delivery is preferred, and operative caesarean section is reserved only for obstetric reasons.

Initially, mild impairment in marrow function may go undetected and pancytopenia may become apparent only during times of stress or increased demand (e.g., bleeding or infection). Varieties of hematopoietic and nonhematopoietic conditions manifest with features of pancytopenia. The underlying mechanisms are: decrease in hematopoietic cell production, marrow replacement by abnormal cells, suppression of marrow growth and differentiation, ineffective hematopoiesis with cell death, defective cell formation which are removed from the circulation, antibody mediated sequestration or destruction of cells and trapping of cells in a hypertrophied and over active reticuloendothelial system. ${ }^{8,9}$

The commonest clinical manifestations of pancytopenia are usually fever $(86.7 \%)$, fatigue $(76 \%)$, dizziness (64\%), weight loss (45.3\%), anorexia (37.3\%), night sweats (28\%), pallor (100\%), bleeding (38.7\%), splenomegaly (48\%), hepatomegaly (21.3\%), and lymphadenopathy is $(14.7 \%) .{ }^{10}$

Bone marrow examination is extremely helpful in evaluation of pancytopenia. ${ }^{3}$ This allows complete assessment of marrow architecture and the pattern of distribution of any abnormal infiltrate and for the detection of focal bone marrow lesions. ${ }^{11,12}$ While bone marrow failure syndromes and malignancies are important causes, certain non-malignant conditions such as infection and nutritional anemia are equally important causes. $^{3}$ The most common causes leading to pancytopenia on bone marrow examination are hypoplastic/aplastic (AA) bone marrow (29.05\%), megaloblastic anemia (MA) (23.64\%), hematological malignancies i.e. acute myeloid leukemia (AML) (21.62\%), and erythroid hyperplasia (EH) (19.6\%). ${ }^{9}$

The relationship of normoblastic erythroid hyperplasia to pancytopenia is found to be uncertain. It is suggested that there is a possibility that some of these cases represent one phase in the evolution of hypoplasia/aplasia, while some may be cases of refractory anemia. Criteria for differentiation of these groups remain unsatisfactory and these patients should be kept under regular hematological follow up. ${ }^{13,14}$

\section{CONCLUSION}

Association of pancytopenia with pregnancy is rare entity with increased risk of poor maternal and fetal outcome, but with proper diagnosis and management there is favourable maternal and fetal outcome. Pregnancies complicated by intrauterine growth retardation, preterm labor, stillbirth, and spontaneous abortion can be successfully followed till term if appropriate diagnostic tests and treatment modalities are employed. In our case we had a successful maternal and fetal outcome. 
Multidisciplinary team approach, intensive targeted therapy, and good financial support are necessary to achieve an optimal outcome.

Funding: No funding sources

Conflict of interest: None declared

Ethical approval: Not required

\section{REFERENCES}

1. Metikurke SH, Rashmi K, Bhavika R. Correlation of bone marrow aspirate, biopsies and touch imprint findings in pancytopenia. J Hematol. 2013;2:8-13.

2. Khodke K, Marwah S, Buxi G, Yadav RB, Chaturvedi NK. Bone marrow examination in cases of pancytopenia. J Indian Academy Clin Med. 2001;2:55-9.

3. Varma N, Dash S. A reappraisal of underlying pathology in adult patients presenting with pancytopenia. Trop Geogr Med. 1992;44:322-7.

4. Deka D, Malhotra N, Sinha A. Pregnancy associated aplastic anemia: maternal and fetal outcome. J Obstet Gynaecol Res. 2003;29:67-72.

5. Deka D, Banerjee N, Roy K. Aplastic anemia during pregnancy: variable clinical course and outcome. Eur J Obstet Gynecol Reprod Biol. 2001;94:152-4.

6. Oosterkamp HM, Brand A, Kluin-Nelemans JC, Vandenbroucke JP. Pregnancy and severe aplastic anaemia: causal relation or coincidence?. $\mathrm{Br} \mathrm{J}$ Haematol. 1998;103:315-6.

7. Yang ZS, Mei-Ying L, Mi W, Xiao-Hui Z. Pregnancy and myelodysplastic syndrome: An analysis of the clinical characteristics, maternal and fetal outcomes. J Maternal-Fetal Neonatal Med. 2015;28(18):2155-9.

8. Shimamura A, Alter BP. Inherited aplastic anemia syndrome. In: Greer JP, Foerster J, Rodgers GM, Paraskevas F, Gladet B, Arber DA, editors. Wintrobe's clinical hematology. Philadelphia: Lippincott Williams and Wilkins; 2008:1173-1261.

9. Jha A, Sayami G, Adhikari RC, Panta AD, Jha R. Bone marrow examination in cases of pancytopenia. J Nepal Med Assoc. 2008;47:12-7.

10. Imbert M, Scoazec JY, Mary JY, Jouzult H, Rochant $\mathrm{H}$, Sultan C. Adult patients presenting with pancytopenia: a reappraisal of underlying pathology and diagnostic procedures in 213 cases. Hematol Pathol. 1989;3:159-67.

11. Bone marrow examination: indication, technique. In: Anesoft, Foucar K, editors. Bone marrow pathology. Hong Kong: American Society Clinical Pathology; 2001:30-47.

12. Nanda A, Basu S, Marwaha N. Bone marrow trephine biopsy as an adjunct to bone marrow aspiration. J Assoc Physicians India. 2002;50:893-5.

13. Kumar DB, Raghupati AR. Clinicohematological analysis of pancytopenia. Basic Applied Pathol. 2012;5:19-21.

14. Liu Y, Du L, Osato M. The zebrafish udu gene encodes a novel nuclear factor and is essential for primitive erythroid cell development. Blood. 2008;110(1):3331-42.

Cite this article as: Rajput Y, Wankhede UN. A rare case report: pregnancy with pancytopenia. Int $\mathbf{J}$ Reprod Contracept Obstet Gynecol 2017;6:5633-5. 